\title{
Profile of secukinumab in the treatment of psoriasis: current perspectives
}

This article was published in the following Dove Press journal:

Therapeutics and Clinical Risk Management

2 December 2015

Number of times this article has been viewed

\author{
Michael Roman \\ Vandana K Madkan \\ Melvin W Chiu \\ Division of Dermatology, David \\ Geffen School of Medicine at UCLA, \\ Los Angeles, CA, USA
}

\begin{abstract}
Secukinumab (Cosentyx $\left.{ }^{\mathrm{TM}}\right)$ is a human monoclonal IgG1k antibody that has been developed to target and block the actions of IL-17A. It is known that this cytokine is elevated in lesions of psoriasis. Interleukins in the Th17 pathway play a pivotal role in the pathogenesis of psoriasis and have thus become targets for recent biologic drug development. As a monoclonal antibody immune modulator, secukinumab exhibits the expected pharmacokinetic properties of slow subcutaneous absorption, low clearance, and long half-life, although formal studies examining the impact of impaired hepatic or renal function on the overall pharmacokinetic profile have not been conducted. Both Phase II and III clinical trials have demonstrated the effectiveness of secukinumab in the treatment of moderate-to-severe plaque psoriasis, psoriatic arthritis, rheumatoid arthritis, ankylosing spondylitis, and noninfectious uveitis. In June 2015, secukinumab was approved by the US Food and Drug Administration for the treatment of adults with moderate-to-severe plaque psoriasis, with a wealth of clinical trials showcasing its efficacy in improving psoriasis area and severity index scores, and it is superior to other comparable biologics on the market, including the TNF inhibitor etanercept. As such, this review focuses on the marquee clinical trials involving secukinumab treatment of plaque psoriasis, while also exploring this drug's efficacy in treating patients with psoriatic arthritis, a disease that has a well-documented comorbidity in patients diagnosed with moderate-to-severe plaque psoriasis. Finally, the safety and tolerability of this drug in a variety of clinical trials to date have also been reviewed, and will undoubtedly have a large impact on this drug's postmarketing surveillance and future studies regarding its long-term safety.
\end{abstract}

Keywords: biologics, IL-17, psoriatic arthritis

\section{Introduction}

Psoriasis is a complex inflammatory disease that occurs in genetically susceptible individuals and presents with the development of erythematous scaly plaques on the skin. In the United States, psoriasis remains a common, immune-mediated disease, affecting 7.4 million adults. Among US adults aged 20 years and older, the prevalence of psoriasis is $3.2 \%{ }^{1}$ About $6 \%-42 \%$ of individuals with psoriasis will develop psoriatic arthritis (PsA), a form of chronic inflammatory arthritis that typically involves painful inflammation of the joints and surrounding connective tissue and can occur in any joint, but most commonly affects the joints of the fingers and toes. ${ }^{2}$

Although early concepts of the pathogenesis of psoriasis focused primarily on keratinocyte hyperproliferation, dysregulation of the immune system is now recognized as a critical event in this disease. There are many cytokines whose serum levels have been found to be elevated in psoriatic patients, including TNF- $\alpha$, IFN- $\gamma$, IL-6, IL- 8 , IL-12, IL-18, and IL-17. ${ }^{3}$ The IL-17 family consists of subtypes A-F, with IL-17A having the most prominent role in host defense and autoimmunity. Although the
Correspondence: Melvin W Chiu

Division of Dermatology, David

Geffen School of Medicine at UCLA,

10833 Le Conte Avenue, Los Angeles,

CA 90095, USA

Tel + I 310825691 I

Email mchiu@mednet.ucla.edu
Therapeutics and Clinical Risk Management 20 I5:I I 1767-I777

1767

Dovepress

http://dx.doi.org/10.2147/TCRM.S79053 (c) (i) (5) 2015 Roman et al. This work is published by Dove Medical Press Limited, and licensed under Creative Commons Attribution - Non Commercial (unported, v3.0) permission from Dove Medical Press Limited, provided the work is properly attributed. Permissions beyond the scope of the License are administered by Dove Medical Press Limited. Information on

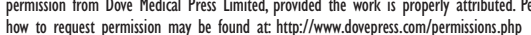


functions of all the subtypes have not yet been identified, IL-17A, B, F, and E have been implicated in various inflammatory processes. IL-17A, along with IL-17F, promotes granulopoiesis, neutrophil accumulation, and neutrophil activation in the lung, joint space, central nervous system, and intestinal tissue. Moreover, IL-23 produced by dendritic cells is responsible for the regulation of IL-17A and IL-17F production by T-lymphocytes. Other important members of the IL-17 pathway include IL-17B and IL-17C, which work with IL-17A and IL-17F to regulate TNF- $\alpha$, IL-1 $\beta$, and local tissue growth factor secretion. IL-17E is another critical member of this family. This particular cytokine is responsible for eosinophil accumulation in the bronchoalveolar space and nonspecific bronchial hyperreactivity. ${ }^{4}$

The cytokine IL-17A is elevated in lesions of psoriasis. Th17 cells are the main producers of IL-17A but other IL-17A producing-cells include $\gamma \delta \mathrm{T}$-cells, innate subtypes of T-cells (iTh17), lymphoid tissue inducer cells, natural killer and natural killer T-cells, macrophages, and Paneth cells. 5,6 IL-17A has many functions that are relevant to psoriasis, including the enhancement of angiogenesis, the promotion of the release of other inflammatory cytokines (TNF- $\alpha$, IL-1, and IL-6), and the direct activation of keratinocytes leading to increased production of chemokines. ${ }^{6}$ Interleukins in the Th17 pathway play a pivotal role in the pathogenesis of psoriasis and have become targets for drug development. ${ }^{7}$

Secukinumab (Cosentyx ${ }^{\mathrm{TM}}$, Novartis AG, Basel, Switzerland) is a human monoclonal IgG1k antibody that has been developed to target and block the actions of IL-17A. In 2010, a proof of concept study by Hueber et $\mathrm{al}^{8}$ demonstrated the efficacy of secukinumab in the treatment of chronic plaque-type psoriasis (36 patients), rheumatoid arthritis (52 patients), and chronic noninfectious uveitis (16 patients). The results of this study further support a role for IL-17A in the pathophysiology of these diverse inflammatory diseases. More recently, both Phase II and III clinical trials have studied secukinumab in the treatment of moderateto-severe plaque psoriasis, PsA (Table 1), and a number of other nonpsoriatic treatments including rheumatoid arthritis, ankylosing spondylitis, and noninfectious uveitis. ${ }^{8-13}$ In contrast, secukinumab was found to be ineffective in treating patients with moderate-to-severe Crohn's disease. Moreover, patients assigned to the $2 \times 10 \mathrm{mg} / \mathrm{kg}$ intravenous (IV) secukinumab treatment group experienced higher rates of adverse events (AEs), such as infection and worsening of Crohn's disease, compared with placebo. ${ }^{14}$ The focus of this review, however, will be on the efficacy and safety of secukinumab in the treatment of moderate to severe plaque psoriasis and PsA.

\section{Secukinumab pharmacokinetics and special patient populations}

At the therapeutic concentrations used in psoriasis, secukinumab fully neutralizes the activity of IL-17A, does not neutralize IL-17F, leaves other functions of Th17 cells intact, and does not directly influence the Th1 pathway. This specific mechanism of action is unique to IL-17 inhibitors and leads to the normalization of skin histology, including achievement of clear to almost clear skin for the majority of patients. Furthermore, this specificity offers the potential for fewer off-target effects when compared to other available current treatment options. ${ }^{15}$ Secukinumab exists in a liquid formulation and can be delivered via either a prefilled syringe ${ }^{16}$ or autoinjector/pen. ${ }^{17}$ This drug is most commonly delivered subcutaneously (but has also been tested intravenously), as will be discussed in the "Efficacy studies" section of this review.

\section{Pharmacokinetics}

Secukinumab pharmacokinetic (PK) and pharmacodynamic markers were evaluated after both intravenous and subcutaneous (SC) administration in healthy volunteers and psoriasis patients. Overall, clinical pharmacology studies demonstrated that secukinumab shows PK properties typical of a human IgG1-type immunoglobulin interacting with the soluble cytokine target IL-17A. Secukinumab's PK profile is typical of a fully human immunoglobulin IgG1 molecule: slow SC absorption, low clearance, and long half-life. There is no evidence of a time-dependent change in clearance. ${ }^{15}$

Given secukinumab's slow SC absorption, peak concentrations were reached between 5 and 6 days postdose in plaque psoriasis patients receiving a single SC 150 or $300 \mathrm{mg}$ dose in various clinical trials. The average bioavailability with SC administration was $73 \%$. These results are in line with the bioavailability estimates of other IgG1 human monoclonal antibodies. ${ }^{18}$ The volume of distribution following single intravenous administration was low, suggesting limited distribution of secukinumab to peripheral compartments. Factors including sex, age, race, and disease severity did not have a clinically meaningful impact on systemic exposure after adjusting for bodyweight.

Human IgG1 monoclonal antibodies are metabolized similarly to endogenous $\mathrm{IgG}$ via intracellular catabolism. The PK of secukinumab is consistent with this disposition pathway, without any evidence for target-mediated 
Table I Efficacy studies of secukinumab

\begin{tabular}{|c|c|c|c|c|}
\hline & Study title & $\begin{array}{l}\text { Total } \\
\text { number of } \\
\text { patients }\end{array}$ & Dosages studied & Primary results \\
\hline \multirow[t]{2}{*}{$\begin{array}{l}\text { Psoriasis, } \\
\text { Phase II }\end{array}$} & $\begin{array}{l}\text { Efficacy and safety of secukinumab in the } \\
\text { treatment of moderate-to-severe plaque } \\
\text { psoriasis }^{20}\end{array}$ & 125 & $\begin{array}{l}\text { Four dose cohorts: } 1 \times 25 \mathrm{mg}(\mathrm{n}=29) \text {, } \\
3 \times 25 \mathrm{mg}(\mathrm{n}=26), \\
3 \times 75 \mathrm{mg}(\mathrm{n}=21), 3 \times 150 \mathrm{mg} \\
(\mathrm{n}=27) \mathrm{SC} \text { at weeks } 0,4, \\
\text { and } 8 \\
\text { Placebo SC }(n=22) \text { at weeks } 0,4 \text {, } \\
\text { and } 8\end{array}$ & $\begin{array}{l}82 \% \text { of the } 3 \times 150 \mathrm{mg} \text { and } 57 \% \text { of } \\
\text { the } 3 \times 75 \mathrm{mg} \text { group versus } 9 \% \text { of } \\
\text { the placebo group achieved PASI } \\
75 \text { by week } 12\end{array}$ \\
\hline & $\begin{array}{l}\text { Secukinumab induction and maintenance } \\
\text { therapy in moderate-to-severe plaque } \\
\text { psoriasis }^{21}\end{array}$ & 404 & $\begin{array}{l}\text { Three I } 50 \text { mg SC induction } \\
\text { doses: single (week } 0 ; n=66 \text { ), early } \\
\text { (weeks } 0,1,2,4 ; n=133 \text { ) and } \\
\text { monthly (weeks } 0,4 \text {, and } 8 ; n=138 \\
\text { patients) } \\
\text { Matching placebo (dosing at } \\
\text { weeks } 0,1,2,4 \text {, and 8) }\end{array}$ & $\begin{array}{l}54.5 \% \text { of early and } 42 \% \text { of } \\
\text { monthly induction regimens } \\
\text { versus } 1.5 \% \text { in placebo group } \\
\text { achieved PASI } 75 \text { at week } 12\end{array}$ \\
\hline \multirow[t]{3}{*}{$\begin{array}{l}\text { Psoriasis, } \\
\text { Phase III }\end{array}$} & $\begin{array}{l}\text { Secukinumab in plaque psoriasis - } \\
\text { results of two Phase III trials }{ }^{23}\end{array}$ & $\begin{array}{l}738 \text { in } \\
\text { ERASURE } \\
\text { trial }\end{array}$ & $\begin{array}{l}\text { ERASURE study: two } \\
\text { secukinumab SC doses at } 300 \text { or } \\
\text { I } 50 \text { mg (once weekly for } 5 \text { weeks, } \\
\text { then every } 4 \text { weeks) } \\
\text { Matching placebo doses }\end{array}$ & $\begin{array}{l}\text { ERASURE study: } 81.6 \% \text { of } \\
300 \mathrm{mg} \text { secukinumab } \\
\text { group, } 71.6 \% \text { of the } 150 \mathrm{mg} \\
\text { secukinumab group, and } 4.5 \% \\
\text { of the placebo group achieved } \\
\text { PASI } 75 \text { at week } 12\end{array}$ \\
\hline & $\begin{array}{l}\text { Secukinumab in plaque psoriasis - } \\
\text { results of two Phase III trials }{ }^{23}\end{array}$ & $\begin{array}{l}\text { I,306 in } \\
\text { FIXTURE } \\
\text { trial }\end{array}$ & $\begin{array}{l}\text { FIXTURE study: same as } \\
\text { ERASURE study plus SC } \\
\text { etanercept } 50 \mathrm{mg} \text { dose } \\
\text { twice weekly for } 12 \text { weeks, } \\
\text { then once weekly }\end{array}$ & $\begin{array}{l}\text { FIXTURE study: } 77.1 \% \text { of the } \\
300 \mathrm{mg} \text { secukinumab group, } \\
67 \% \text { of the } 150 \mathrm{mg} \text { secukinumab } \\
\text { group, } 44 \% \text { of the etanercept } \\
\text { group, and } 4.9 \% \text { of the placebo } \\
\text { group achieved PASI } 75 \text { by } \\
\text { week } 12\end{array}$ \\
\hline & $\begin{array}{l}\text { Secukinumab is superior to ustekinumab } \\
\text { in clearing skin of subjects with } \\
\text { moderate to severe plaque psoriasis: } \\
\text { CLEAR, a randomized controlled trial }{ }^{26}\end{array}$ & 676 & $\begin{array}{l}\text { Two treatment groups: secukinumab } \\
300 \mathrm{mg} \text { or ustekinumab per label } \\
\text { ( } 45 \mathrm{mg} \text { for subjects }<100 \mathrm{~kg} \text { at } \\
\text { baseline; } 90 \mathrm{mg} \text { for subjects }>100 \mathrm{~kg} \\
\text { at baseline }\end{array}$ & $\begin{array}{l}79.0 \% \text { of secukinumab patients } \\
\text { versus was superior to }(57.6 \%) \\
\text { of ustekinumab patients achieved } \\
\text { PASI } 90 \text { response at week } 16 \\
(P<0.000 \text { I })\end{array}$ \\
\hline $\begin{array}{l}\text { Psoriasis, } \\
\text { Phase III } \\
\text { subanalysis }\end{array}$ & $\begin{array}{l}\text { Secukinumab efficacy and safety in } \\
\text { Japanese patients with moderate-to- } \\
\text { severe plaque psoriasis }^{25}\end{array}$ & 87 & Same as ERASURE study & $\begin{array}{l}82.8 \% \text { of the } 300 \mathrm{mg} \\
\text { secukinumab group, } 86.2 \% \text { of } \\
\text { the } 150 \mathrm{mg} \text { secukinumab group, } \\
\text { and } 6.9 \% \text { of the placebo group } \\
\text { achieved PASI } 75 \text { by week } 12\end{array}$ \\
\hline $\begin{array}{l}\text { Psoriatic } \\
\text { arthritis, } \\
\text { Phase II }\end{array}$ & $\begin{array}{l}\text { Efficacy and safety of secukinumab, } \\
\text { a fully human anti-IL-I7A } \\
\text { monoclonal antibody, in patients } \\
\text { with moderate-to-severe psoriatic } \\
\text { arthritis }^{28}\end{array}$ & 42 & $\begin{array}{l}\text { Two } 10 \mathrm{mg} / \mathrm{kg} \text { IV doses } 3 \text { weeks } \\
\text { apart }(\mathrm{n}=28) \\
\text { Two matching placebo doses } \\
3 \text { weeks apart }(\mathrm{n}=14)\end{array}$ & $\begin{array}{l}39 \% \text { of the secukinumab group } \\
\text { versus } 23 \% \text { of the placebo group } \\
\text { achieved ACR } 20 \text { responses at } \\
\text { week } 6\end{array}$ \\
\hline $\begin{array}{l}\text { Psoriatic } \\
\text { arthritis, } \\
\text { Phase III }\end{array}$ & $\begin{array}{l}\text { Secukinumab inhibition of IL-I7A in } \\
\text { patients with psoriatic arthritis }{ }^{29}\end{array}$ & 606 & $\begin{array}{l}\text { Three treatment groups: } \\
\text { secukinumab I } 50 \mathrm{mg} \text { IV } \\
(10 \mathrm{mg} / \mathrm{kg}), 75 \mathrm{mg} \text { IV (I0 mg/kg), } \\
\text { or placebo. All treatment groups } \\
\text { received either IV secukinumab or } \\
\text { placebo doses at weeks } 0,2 \text {, and } \\
4 \text {, followed by SC secukinumab or } \\
\text { placebo }\end{array}$ & $\begin{array}{l}50 \% \text { of patients in the } \\
\text { secukinumab } 150 \mathrm{mg} \text { group } \\
\text { and } 50.5 \% \text { of patient in the } \\
\text { secukinumab } 75 \mathrm{mg} \text { group } \\
\text { achieved ACR } 20 \text { response } \\
\text { rates at week } 24 \text { compared to } \\
\text { only } 17.3 \% \text { of placebo patients } \\
(P<0.00 \mathrm{I})\end{array}$ \\
\hline & $\begin{array}{l}\text { Secukinumab, a human anti-IL-I7A } \\
\text { monoclonal antibody, in patients } \\
\text { with psoriatic arthritis (FUTURE 2): } \\
\text { a randomized, double-blind, placebo- } \\
\text { controlled, Phase III trial }{ }^{30}\end{array}$ & 397 & $\begin{array}{l}3 \text { dose cohorts: secukinumab } \\
\text { SC } 300 \text {, I50, or } 75 \mathrm{mg} \text { once a } \\
\text { week from baseline and then every } \\
4 \text { weeks from week } 4 \\
\text { Matching placebo SC dosing }\end{array}$ & $\begin{array}{l}54 \% \text { of the } 300 \mathrm{mg} \text { group, } 51 \% \\
\text { of the } 150 \mathrm{mg} \text { group, and } 29 \% \\
\text { of the } 75 \mathrm{mg} \text { group versus I } 5 \% \\
\text { of placebo group achieved an } \\
\text { ACR20 at week } 24\end{array}$ \\
\hline
\end{tabular}

Abbreviations: SC, subcutaneous; PASI, psoriasis area and severity index score; IV, intravenous; ACR20, American College of Rheumatology response criteria; PsA, psoriatic arthritis. 
disposition. Clearance is dose- and time-dependent, with slow serum clearance.

Clearance of secukinumab in geriatric patients and patients $<65$ years of age was similar. However, formal studies addressing pediatrics have not been conducted. Because secukinumab is a human IgG with a large molecular size $(\sim 150 \mathrm{kDa})$ and because intact immunoglobulin is filtered by the kidney only to a very small degree, only very small amounts of antibody are expected to be excreted in the urine. Thus, renal impairment is not likely to influence urinary excretion and the overall PK profile. Formal studies examining the impact of impaired renal function on urinary excretion and overall PK profile have not been conducted. Finally, hepatic impairment would not be expected to influence metabolism or excretion of human $\operatorname{IgG}$. As is the case with geriatric patients and renal impairment, no formal studies were conducted to examine the impact of impaired hepatic function on the pharmacokinetics of secukinumab. ${ }^{15}$

\section{Drug interactions}

As mentioned before, secukinumab's main route of elimination is via intracellular catabolism and thus the potential for drug interactions between secukinumab and small drug molecules is low. In addition, cytochrome P450 enzyme inhibitors and inducers are unlikely to affect the secukinumab exposure-response relationships, given that hepatic metabolizing enzymes, such as cytochrome P450 and uridine 5'-diphospho-glucuronosyltransferases (UGTs), are not presumed to be involved with monoclonal antibody elimination. Other monoclonal antibodies used in treating psoriasis, including infliximab and adalimumab, have been noted to have decreased clearances when administered with methotrexate. However, PK results in a dose-finding study with secukinumab in rheumatoid arthritis patients indicated that methotrexate does not have an impact on the disposition of secukinumab. ${ }^{18,19}$

\section{Efficacy studies}

\section{Phase II trials}

Several clinical trials have demonstrated the efficacy of secukinumab in psoriasis patients. The first study was a randomized, international, multicenter, double-blind, placebocontrolled, Phase II dose-ranging trial that was published in $2013 .{ }^{20}$ In this study, 125 psoriasis patients were recruited at multiple centers. Patients were randomized in a 1:1:1:1:1 ratio to five treatment groups: one $\mathrm{SC}$ secukinumab $25 \mathrm{mg}$ dose, three $25 \mathrm{mg}$ doses, three $75 \mathrm{mg}$ doses, three $150 \mathrm{mg}$ doses, or matching placebo doses. Patients were given doses at weeks 0,4 , and 8 . The first treatment group received $25 \mathrm{mg}$ of secukinumab at week 0 , then placebo doses at weeks 4 and 8 . The placebo group received placebo at weeks 0,4 , and 8 . At the end of the 12-week treatment period, patients entered a follow-up period of 24 weeks. The primary end point of this study was defined as achieving psoriasis area and severity index score (PASI) of 75 after 12 weeks of treatment.

After 12 weeks, $82 \%$ of the $3 \times 150 \mathrm{mg}$ and $57 \%$ of the $3 \times 75 \mathrm{mg}$ group versus $9 \%$ of the placebo group achieved PASI 75 by week 12. This study demonstrated the superior efficacy of secukinumab compared to placebo in improving signs and symptoms of moderate-to-severe plaque psoriasis given that $\mathrm{SC}$ secukinumab $3 \times 75 \mathrm{mg}$ and $3 \times 150 \mathrm{mg}$ achieved the primary outcome of PASI 75 response after 12 weeks. $^{20}$

Another Phase II trial published in 2013 used a randomized, double blind, placebo-controlled, regimen-finding study design to assess the efficacy of secukinumab. ${ }^{21}$ This international study included a 12-week induction period, a 20-week maintenance period, and a follow-up period beginning at week 32 after initial treatment. During the 12 week induction period, patients were randomly assigned in a $1: 2: 2: 1$ ratio to one of three different SC secukinumab $150 \mathrm{mg}$ dosing schedules: single (dosing at week 0 ), monthly (dosing at weeks 0,4 , and 8), or early (dosing at weeks 0 , 1,2 , and 4); or to matching placebo (dosing at weeks 0,1 , 2,4 , and 8). At week 12, patients were categorized into one of three categories based on treatment outcome: responding patients (those achieving PASI 75), nonresponders (patients not achieving PASI 50), and partial responders (patients achieving PASI 50, but not PASI 75). After 12 weeks, a new category of patient was created: patients in whom two consecutive relapses (defined as at least $50 \%$ loss of best PASI gain achieved previously during the study) were observed at scheduled visits from week 12 onwards.

Patients in the responding category were rerandomized (1:1) at week 12 to one of two regimens for the 20 -week maintenance period: either treatment at fixed intervals (SC secukinumab $150 \mathrm{mg}$ at weeks 12 and 24 and placebo at a regularly scheduled study visit at which a start of relapse was observed) or treatment at start of relapse (placebo administration at week 12 and at week 24 in the absence of start of relapse, and SC secukinumab $150 \mathrm{mg}$ at start of relapse detected during a regularly scheduled study visit). Start of relapse was defined as loss of one-third of maximum PASI improvement achieved at any visit after week 12. On the other hand, patients in the other three 
categories (nonresponders, partial responders, and relapsing patients) entered an open-label phase at week 12, in which they received SC secukinumab $150 \mathrm{mg}$ every 4 weeks until week 32. The primary outcome was achievement of PASI 75 after 12 weeks of treatment.

After 12 weeks, $54.5 \%$ of the early regimen and $42 \%$ of the monthly regimen resulted in PASI 75 response rates versus only $1.5 \%$ of the placebo regimen. Among PASI 75 responders entering the maintenance period, $85 \%$ of fixed-interval regimen patients achieved PASI 75 and 58\% achieved PASI 90 at least once from week 20 to 28 versus 67\% PASI 75 achievement and 21\% PASI 90 achievement for the start-of-relapse regimen. This study concluded that secukinumab shows efficacy for both induction and maintenance treatment of moderate-to-severe plaque psoriasis. ${ }^{21}$ Of note, Mrowietz et $\mathrm{al}^{22}$ performed a double blind, noninferiority trial (SCULPTURE) comparing secukinumab retreatment-as-needed versus a fixed-interval regimen. Secukinumab fixed interval showed clear benefit versus the study-specified retreatment-as-needed regimen for maintaining efficacy from week 12 to 52 of treatment.

\section{Phase III trials}

Phase III clinical trials have confirmed the Phase II findings (as already mentioned) and have demonstrated the efficacy of secukinumab in the treatment of moderate-to-severe plaque psoriasis. Langley et $\mathrm{al}^{23}$ conducted two Phase III, double-blind, multicenter, randomized, placebo-controlled, parallel group, 52-week trials called ERASURE (Efficacy of Response and Safety of Two Fixed Secukinumab Regimens in Psoriasis) and FIXTURE. The FIXTURE study was also active-controlled using etanercept. For both studies, the study inclusion criteria were as follows: 1) 18 years of age or older; 2) moderate-to-severe plaque psoriasis that had been diagnosed at least 6 months before randomization and that was poorly controlled with topical treatments, phototherapy, systemic therapy, or a combination of these therapies; 3) PASI score of 12 or higher; 4) an investigator's global assessment (IGA) score of 3 or 4; and 5) involvement of $10 \%$ or more of the body surface area.

Both studies consisted of a screening period of 1-4 weeks, a 12-week induction period, a 40-week maintenance period, and an 8-week follow-up period. In the ERASURE study, patients were randomized in a 1:1:1 ratio to three groups: $300 \mathrm{mg}$ secukinumab, $150 \mathrm{mg}$ secukinumab, or placebo. In the FIXTURE study, patients were randomized in a 1:1:1:1 ratio to four groups: $300 \mathrm{mg}$ secukinumab, $150 \mathrm{mg}$ secukinumab, $50 \mathrm{mg}$ etanercept, or placebo. In both studies, patients in the $300 \mathrm{mg}$ secukinumab group received two $150 \mathrm{mg}$ SC secukinumab injections, while patients in the $150 \mathrm{mg}$ secukinumab group received one $150 \mathrm{mg}$ secukinumab injection plus one placebo injection. Regardless of the group, both injections were administered once weekly at baseline and at weeks 1, 2, 3, and 4 and then every 4 weeks until week 48. In the FIXTURE study, patients randomly assigned to etanercept received $50 \mathrm{mg}$ administered subcutaneously twice weekly from baseline until week 12 and then once weekly through week 51. In addition, a double dummy design was maintained in this study with the placebo group receiving placebo injections corresponding to the secukinumab and the etanercept regimens, while the secukinumab and etanercept groups received placebo injections corresponding to the other active-drug regimen. In the ERASURE study, patients in the placebo group received matching placebo injections corresponding to the secukinumab treatment groups. The primary end points in both studies were achievement of PASI 75 and an IGA response of 0 or 1 by week 12. Multiple other secondary end points in both studies included PASI 90 achievement by week 12 and PASI 50, 75, 90, and 100 achievements until week 52.

At week 12 of the ERASURE study, $81.6 \%$ of the $300 \mathrm{mg}$ secukinumab group, $71.6 \%$ of the $150 \mathrm{mg}$ secukinumab group, and $4.5 \%$ of the placebo group achieved PASI 75. Similarly in the FIXTURE study, $77.1 \%$ of the $300 \mathrm{mg}$ secukinumab group, $67.0 \%$ of the $150 \mathrm{mg}$ secukinumab group, $44.0 \%$ of the etanercept group, and $4.9 \%$ of the placebo group achieved PASI 75 by week 12 . The median time to $50 \%$ reduction in mean PASI score was 3.0 weeks and 3.9 weeks in the $300 \mathrm{mg}$ and $150 \mathrm{mg}$ secukinumab groups respectively, versus 7 weeks in the etanercept group $(P<0.001)$. With regard to IGA, $65.3 \%$ of the $300 \mathrm{mg}$ secukinumab group, $51.2 \%$ of the $150 \mathrm{mg}$ secukinumab group, and $2.4 \%$ of the placebo group in the ERASURE study achieved a score of 0 or 1 by week 12. Likewise, in the FIXTURE study, $62.5 \%$ of the $300 \mathrm{mg}$ secukinumab group, $51.1 \%$ of the $150 \mathrm{mg}$ secukinumab group, $27.2 \%$ of the etanercept group, and $2.8 \%$ of the placebo group achieved an IGA score of 0 or 1 by week 12 . The authors of these two studies concluded that IL-17A is valid therapeutic target given secukinumab's effectiveness in the treatment of moderate-to-severe plaque psoriasis. $^{24}$

Similarly, Ohtsuki et $\mathrm{al}^{25}$ conducted their own subanalysis of Langley et al's ${ }^{23}$ ERASURE study in order to assess secukinumab efficacy and safety in Japanese patients with moderate-to-severe plaque psoriasis. The ERASURE study was conducted at 88 sites (738 patients), including 18 sites 
in Japan (87 patients). Since the outcomes of the ERASURE study in the overall population were already presented in the Langley et $\mathrm{al}^{23}$ study, the purpose of this subanalysis was to focus on data pertaining to the Japanese patients from ERASURE. The details of the ERASURE study design have been discussed. The authors of this study chose two primary end points to analyze: PASI 75 achievement and IGA score of 0 or 1 combined with a two-point improvement from baseline score at week 12. Secondary endpoints used in this study included PASI 90 at week 12, PASI 75/90/100 and IGA scores of 0 or 1 up to week 52, and achievement of a score of 0 or 1 on the dermatology life quality index at week 12 or week 52 .

By week 12, 82.8\% of the $300 \mathrm{mg}$ secukinumab group, $86.2 \%$ of the $150 \mathrm{mg}$ secukinumab group, and $6.9 \%$ of the placebo group achieved PASI 75. In addition, $55.2 \%$ of the $300 \mathrm{mg}$ secukinumab group, $55.2 \%$ of the $150 \mathrm{mg}$ secukinumab group, and $3.4 \%$ of the placebo group achieved a 0 or 1 IGA score by week 12 . Furthermore, $62.1 \%$ of the $300 \mathrm{mg}$ secukinumab group and $55.2 \%$ of the $150 \mathrm{mg}$ secukinumab group achieved PASI 90 by week 12 versus $0 \%$ of the placebo group. It was concluded that secukinumab showed robust efficacy in symptom reduction for moderate-to-severe plaque psoriasis in these Japanese patients. ${ }^{25}$

Treatment of plaque psoriasis with secukinumab yields relatively rapid improvements in disease course and sustained improved results. Data from ERASURE, FIXTURE, and other studies demonstrates that the $300 \mathrm{mg}$ SC dose achieves peak effects at week 16 and sustains efficacy to week 52 of treatment. ${ }^{15,23}$ Moreover, speed of response data from the FIXTURE trial in particular demonstrated that patients in the $300 \mathrm{mg}$ secukinumab group achieved a 50\% reduction from mean baseline PASI score at 3 weeks of treatment, compared to 3.9 weeks for the $150 \mathrm{mg}$ secukinumab group and 7 weeks for the etanercept group. ${ }^{23}$

Similar to the FIXTURE trial's use of an active comparator (etanercept) to demonstrate favorable results in the use of secukinumab over etanercept in psoriasis patients, the CLEAR study, a Phase IIIB trial, also shows improved PASI scores of secukinumab over an active comparator, this time ustekinumab. CLEAR is a 52-week, multicenter, randomized, double-blind study in patients with moderate-tosevere plaque psoriasis. ${ }^{26}$ The CLEAR trial's preliminary data points reflect head-to-head data between secukinumab versus ustekinumab with a primary end point of PASI 90 at week 16. At week $16,79 \%$ of secukinumab patients achieved a PASI 90 versus $57.6 \%$ of those on ustekinumab. The secondary end point found $50 \%$ of secukinumab patients achieved
PASI 75 at week 4, compared to $20.6 \%$ of ustekinumab patients. In a novel trial data marker, clear skin or a PASI 100 was achieved at week 16 by $44.3 \%$ of patients treated with secukinumab compared with $28.4 \%$ of patients receiving ustekinumab. The safety profile of secukinumab was comparable to ustekinumab and consistent with previously reported Phase III clinical trials for secukinumab. ${ }^{26}$

While the CLEAR trial and the aforementioned Phase III trials illustrated the efficacy and superiority of secukinumab in the treatment of moderate-to-severe plaque psoriasis, the STATURE trial by Thaçi et $\mathrm{al}^{27}$ explored the method of secukinumab administration in the context of improving treatment response in partial responders (patients with PASI score improvement of $\geq 50 \%$ but $<75 \%$ ). STATURE was a recently published randomly controlled Phase III trial which demonstrated that responses to secukinumab in partial responders may be improved by continued dosing with $300 \mathrm{mg}$ SC, or by higher exposure - either via escalation from 150 to $300 \mathrm{mg}$ SC or to an IV regimen - without differences in the safety profile. These results were not significant, however, as the coprimary end points of PASI 75 and IGA 0/1 response rates at week 8 (IV versus SC) were not met. The authors of this study attributed this failure of statistical significance to the small sample size of 43 participants. ${ }^{27}$ Further studies addressing this topic are surely warranted.

\section{PsA Phase II trials}

In addition to being studied in context of treating moderateto-severe plaque psoriasis, the efficacy of secukinumab in the treatment of moderate-to-severe PsA has also been examined. In 2014, McInnes et $\mathrm{al}^{28}$ used a randomized, double-blind, placebo-controlled Phase II study design to evaluate the efficacy and safety of secukinumab in the context of moderateto-severe PsA treatment. This study was conducted over a 19-month period and patients were distributed at eleven international centers. Forty-two patients were randomly assigned in a 2:1 ratio to two treatment regimens: two doses of secukinumab $10 \mathrm{mg} / \mathrm{kg}$ IV or placebo. Secukinumab or placebo was administered IV at day 1 (baseline) and then at day 22. Patients were then observed for up to 21 weeks after this second dose. The primary endpoint of the study was the proportion of patients achieving an ACR20 response (American College of Rheumatology response criteria) at week 6.

At week 6, 39\% of the secukinumab group achieved ACR20 responses versus $23 \%$ of the placebo group. Likewise, at week 20, 39\% of secukinumab group achieved ACR20 responses versus $15 \%$ of the placebo group. By week $24,43 \%$ 
of the secukinumab group achieved ACR20 responses versus $18 \%$ of the placebo group. In addition, at week $6,21.7 \%$ of the secukinumab group achieved a "good" European league against rheumatism response versus $9.1 \%$ of the placebo patients. Although the primary end point was not met due to a statistically insignificant difference between secukinumab and placebo treatment groups, this study concluded that secukinumab has some clinical benefit in the treatment of PsA given that clinical responses, acute-phase reactant, and quality of life improvements were greater with secukinumab versus placebo. Given that this particular study only included 42 patients, the authors believe that larger clinical trials of secukinumab in PsA are warranted. ${ }^{28}$

\section{PsA Phase III trials}

Following the success secukinumab demonstrated in treating PsA in Phase II trials, Mease et $\mathrm{a}^{29}$ sought to further explore secukinumab's efficacy using the FUTURE 1 study group. FUTURE 1 is an ongoing, 2-year, Phase III study assessing the effect of secukinumab on signs and symptoms, physical well-being, joint structural damage, and patient-reported quality of life among individuals with PsA. This was a double-blind, Phase III study, in which 606 PsA patients were randomly assigned to one of three treatment groups: secukinumab $10 \mathrm{mg} / \mathrm{kg}$ then subsequent secukinumab $150 \mathrm{mg}$ subcutaneously, $10 \mathrm{mg} / \mathrm{kg}$ IV followed by secukinumab $75 \mathrm{mg}$ subcutaneously, or placebo. All treatment groups received either IV secukinumab or placebo doses at weeks 0,2 , and 4 , followed by SC secukinumab $150 \mathrm{mg}$ or $75 \mathrm{mg}$ or placebo every 4 weeks. Patients in the placebo group were switched to SC secukinumab at a dose of $150 \mathrm{mg}$ or $75 \mathrm{mg}$ at week 16 or 24, depending on clinical response.

The primary end point was the proportion of patients with an ACR20 response at week 24, defined as a 20\% improvement from baseline in the number of tender and swollen joints. Secondary end points included the ACR50 response and joint structural damage secondary to treatment. Fifty percent of patients in the secukinumab $150 \mathrm{mg}$ group and $50.5 \%$ of patient in the secukinumab $75 \mathrm{mg}$ group achieved ACR20 response rates at week 24 compared to only $17.3 \%$ of placebo patients $(P<0.001$ for both comparisons with placebo). Furthermore, clinical improvements with secukinumab were sustained through 52 weeks of treatment. This study further justifies IL-17A as an important therapeutic target given that secukinumab was shown to be more effective than placebo in treating patients with PsA. ${ }^{29}$

In 2015, McInnes et $\mathrm{al}^{30}$ conducted another study, called FUTURE 2, evaluating the efficacy and safety of secukinumab in the treatment of patients with PsA. This was a Phase III, double-blind, placebo-controlled study undertaken at 76 centers globally in which 397 adults $\geq 18$ years old with active PsA were randomly assigned in a 1:1:1:1 ratio to four different treatment groups. The first three groups received SC secukinumab $300 \mathrm{mg}, 150 \mathrm{mg}$, or $75 \mathrm{mg}$ once a week from baseline for 4 weeks and then every 4 weeks afterwards. The fourth treatment group received SC placebo for that same time frame. The primary end point was the proportion of patients achieving ACR20 by week 24 .

By week 24, 54\% of the $300 \mathrm{mg}$ group, $51 \%$ of the $150 \mathrm{mg}$ group, and $29 \%$ of the $75 \mathrm{mg}$ group achieved an ACR 20 versus only $15 \%$ of the placebo group. $P$-values were significant only for the $300 \mathrm{mg}$ and $150 \mathrm{mg}$ treatment groups. Up to week 16 of treatment, the most common adverse effects reported by patients in the secukinumab treatment groups were upper respiratory tract infections and nasopharyngitis, both of which occurred with similar frequency in the placebo group. No deaths were reported. Based on these results, the authors of this study concluded that SC secukinumab $300 \mathrm{mg}$ and $150 \mathrm{mg}$ improved the signs and symptoms of PsA, providing further support for its role as a future treatment option for this cohort of patients. ${ }^{30}$

\section{Patient-reported outcomes}

With regards to patient-reported outcomes, 39\% of patients across two multicenter, randomized, double-blind, placebocontrolled trials chose to participate in the Psoriasis Symptom Diary. ${ }^{23}$ The following symptoms were reported by patients to have improved at week 12 compared to placebo: itching, pain, and scaling. ${ }^{15}$ Additionally, Gottlieb et al ${ }^{31}$ recently conducted physical function improvement sub analyses of the aforementioned ERASURE and FIXTURE trials. Using the Health Assessment Questionnaire-Disability Index (HAQ-DI) as an assessment tool, the analyses showed that mean change from baseline in HAQ-DI was greater with secukinumab $300 \mathrm{mg}$ versus placebo at week 12 in both trials, with greater responses were seen in subjects with larger baseline disability (HAQ-DI $\geq 05){ }^{31}$

\section{Secukinumab safety and tolerability}

Commonly reported side effects from clinical trials of secukinumab are summarized in Table 2. The two Phase III clinical trials mentioned, ERASURE and FIXTURE, included a total of 2,044 patients. During the 12-week induction period in the ERASURE study, $55.1 \%$ of patients had at least one $\mathrm{AE}$ in the $300 \mathrm{mg}$ secukinumab group versus $60.4 \%$ in the $150 \mathrm{mg}$ secukinumab group. On the other hand, $47.0 \%$ of 
Table 2 Common adverse effects of secukinumab treatment

\begin{tabular}{|c|c|}
\hline Clinical studies & $\begin{array}{l}\text { Most common adverse effects } \\
\text { (\% of total patients on secukinumab } \\
\text { regimen during entire trial) }\end{array}$ \\
\hline Langley et $\mathrm{a}^{23}$ & Nasopharyngitis (24.6\%) \\
\hline \multirow[t]{2}{*}{ (FIXTURE study) } & Headache (II.2\%) \\
\hline & Diarrhea (7.9\%) \\
\hline \multirow[t]{5}{*}{ Mclnnes et $\mathrm{al}^{28}$} & Nasopharyngitis (25.0\%) \\
\hline & Headache $(21.4 \%)$ \\
\hline & Neutropenia (21.4\%) \\
\hline & Nausea $(14.3 \%)$ \\
\hline & Dizziness (I4.3\%) \\
\hline \multirow[t]{4}{*}{ Rich et $\mathrm{al}^{21}$} & Nasopharyngitis (16.1\%) \\
\hline & Neutropenia (6.3\%) \\
\hline & Headache $(5.9 \%)$ \\
\hline & Upper respiratory tract infection (4.2\%) \\
\hline \multirow[t]{4}{*}{ Papp et $\mathrm{al}^{20}$} & Nasopharyngitis (I2.6\%) \\
\hline & Neutropenia (7.4\%) \\
\hline & Headache $(4.9 \%)$ \\
\hline & Pharyngitis (2.9\%) \\
\hline Ohtsuki et $\mathrm{al}^{25}$ & Nasopharyngitis (33.7\%) \\
\hline
\end{tabular}

patients in the placebo group had at least one AE. In the $300 \mathrm{mg}$ secukinumab group and the $150 \mathrm{mg}$ secukinumab group, $29.4 \%$ and $26.9 \%$ of the subjects, respectively, had infections compared with $16.2 \%$ of the placebo group during the 12 -week induction period. The most common AEs in the 12 -week induction period and the entire treatment period overall were upper respiratory tract infection, nasopharyngitis, and headache. The incidence of adverse effects in all other system organ classes was similar between the study groups.

In the FIXTURE study, the incidences of AEs during the induction period and the entire treatment period were similar in the secukinumab and etanercept groups. In contrast to the ERASURE study, nasopharyngitis, headache, and diarrhea were the most common AEs in the secukinumab groups during the 12-week induction and the entire treatment period. Seven patients $(0.7 \%)$ in the combined secukinumab groups versus 36 patients $(11.1 \%)$ in the etanercept group experienced injection-site reactions during the entire study.

During the 12-week induction period of the FIXTURE study, $26.7 \%$ of the $300 \mathrm{mg}$ secukinumab group, $30.9 \%$ of the $150 \mathrm{mg}$ secukinumab group, $24.5 \%$ of the etanercept group, and $19.3 \%$ of the placebo group experienced infections and infestations. More specifically, Candida infections were more common with secukinumab than with etanercept during the entire treatment period. Over the entire treatment period, $4.7 \%$ of the $300 \mathrm{mg}$ secukinumab group and $2.3 \%$ of the $150 \mathrm{mg}$ secukinumab group reported mild or moderate Candida infection. All of the infections resolved on their own or with standard therapy, and none resulted in chronic mucocutaneous candidiasis or discontinuation of secukinumab. In the etanercept group, $1.2 \%$ of patients had Candida infection, two of whom had an infection that was graded as severe. No infections or any other AEs were reported in these patients. There were no deaths during the treatment period in either study, and there were no differences in the numbers or types of nonfatal serious AEs in the secukinumab, etanercept, and placebo groups. However, discontinuations due to AEs were more frequent in the etanercept group than in either secukinumab group. ${ }^{23}$

IL-17A plays a key role in host mucocutaneous microbial surveillance. More specifically, Huang et a ${ }^{32}$ found that, compared to wild-type mice, murine (m) IL-17A receptor knockout mice had substantially decreased survival when exposed to systemic challenge with Candida albicans. It was concluded that the mIL-17A/mIL-17AR system is required for normal fungal host defense in vivo. Furthermore, the authors suggested that IL-17A could have potential as a therapeutic cytokine for systemic C. albicans infections in immunocompromised patients with cancer or advanced acquired immunodeficiency syndrome. ${ }^{32}$ This finding provides a strong explanation for why a higher percentage of patients in the secukinumab treatment groups experienced Candida infections. Continued vigilance with respect to the potential for Candida infection will be necessary for secukinumab and future IL-17A inhibitors.

Treatment-emergent anti-secukinumab antibodies, defined as negative at baseline and positive after start of secukinumab treatment, were detected in $0.4 \%$ of the 980 secukinumabtreated patients in the FIXTURE study. However, no patient had neutralizing antibodies, and there was no association with AEs or loss of efficacy. No testing was performed for anti-etanercept antibodies. In the ERASURE study, antisecukinumab antibodies were detected in 2 of 702 subjects receiving secukinumab. Both subjects were receiving $150 \mathrm{mg}$ of secukinumab. In one of the two subjects, anti-secukinumab antibodies were classified as neutralizing antibodies, and were not associated with AEs or loss of efficacy. Loss of efficacy was defined as an increase in PASI score by six points from the minimum PASI score achieved on treatment. Anti-secukinumab antibodies were detected at baseline, before treatment, in eight subjects and persisted postbaseline in three of these subjects. PK data were normal.

Among the exclusion criteria for the ERASURE and FIXTURE trials, was use of methotrexate and other systemic immunomodulating treatments. Patients on these medications were required to undergo a 4-week washout period prior to 
randomization. If the prohibited treatment was used during the study for any indication, the subject was required to discontinue use of the prohibited treatment if he/she wished to continue in the study. ${ }^{23}$ As such, minimal, if any, conclusions can be drawn regarding the relationship between methotrexate use and anti-secukinumab antibody levels in this particular patient population. Moreover, although we could not find data showing that methotrexate reduces the incidence of anti-secukinumab antibodies, data from its use in other biologics suggests it would. ${ }^{33}$

Neutropenia is an important adverse effect that must be considered when administering secukinumab to patients. It is known that IL-17A stimulates granulopoiesis and neutrophil trafficking. ${ }^{34}$ McInnes et $\mathrm{al}^{28}$ found events of leukopenia in eight secukinumab patients and one placebo patient, all Common Terminology Criteria Grade 1. In addition, neutropenia events were observed in six secukinumab patients and one placebo patient. ${ }^{28}$ Similarly, Rich et $\mathrm{al}^{21}$ found Grade 1 or 2 neutropenia in 19 secukinumab patients and one placebo patient in the 12-week induction phase and in 30 secukinumab patients in the maintenance phase (weeks 12-32). Dosing was not interrupted or held as no clinically significant AEs were associated with the development of neutropenia. The neutropenia resolved during the course of the study in all cases. No cases of Grade 3 or 4 neutropenia were reported, and no clinically significant AEs were associated with the development of neutropenia. Furthermore, no patients discontinued the study due to neutropenia. ${ }^{21}$ Similarly, during the FIXTURE trial, Grade 1 and 2 neutropenias were more frequently observed in the secukinumab groups versus placebo, but there was no indication of any dose-related effects. In one patient, Grade 3 neutropenia was reported first while on placebo during the induction period and then again after being rerandomized to the secukinumab $300 \mathrm{mg}$ group during the maintenance period. ${ }^{23}$ Finally, Papp et $\mathrm{al}^{20}$ found decreases in absolute neutrophils in two patients in the $150 \mathrm{mg}$ secukinumab treatment group of their study.

In terms of interactions with concurrent vaccinations, secukinumab was found to have no adverse effects on vaccine administration. As assessed by the achievement of protective antibody levels, Chioato et $\mathrm{a}^{35}$ demonstrated that blockade of IL-17A by secukinumab did not appear to interfere with efficacy of T-cell-dependent influenza and T-cell-independent meningococcal vaccinations. Eighty percent of subjects exposed to secukinumab and $76 \%$ of subjects exposed to no treatment achieved $\mathrm{a}>4$-fold protective immune response to both vaccinations at 4 weeks. Therefore, patients receiving secukinumab may receive concurrent inactivated or nonlive vaccinations. ${ }^{14}$ Live vaccines, however, should not be given concomitantly with secukinumab. ${ }^{35}$

Special monitoring is indicated for patients with active Crohn's disease who are treated with secukinumab. In a collection of four placebo-controlled Phase III trials, there were a total of 59 patients with previously diagnosed Crohn's disease. Three out of 3,430 patients treated with secukinumab experienced exacerbations of their Crohn's disease, all were severe AEs on $150 \mathrm{mg}$ secukinumab. Two were considered flare of existing disease in patients with prior history of Crohn's disease and one was a new event occurring in a patient with symptoms at baseline suggestive of possible active undiagnosed Crohn's disease. Of the two cases with flare, one resolved with treatment, one was ongoing at the time of reporting, and both led to discontinuation of secukinumab. The new exacerbation resolved with treatment and did not cause study drug discontinuation. No cases of Crohn's disease were reported for $300 \mathrm{mg}$ secukinumab or placebo.

Similarly, in that same pool of four placebo-controlled Phase III trials, hypersensitivity AEs were reported in a higher proportion of patients in the secukinumab dose groups compared with placebo. Urticaria was most frequently reported with secukinumab without an apparent dose relation in the initial 12 weeks. Cases of urticaria were nonserious, mostly mild to moderate in severity and not accompanied by other severe hypersensitivity-related AEs. Comparable proportions of secukinumab patients reported administration reactions as those with placebo. Of 54 cases of urticaria, 2, 1 with $300 \mathrm{mg}$ secukinumab and 1 with placebo, were reported as severe. The severe case on $300 \mathrm{mg}$ also led to discontinuation of study treatment; no other cases of urticaria caused discontinuation. The severe case on placebo was associated with angioedema and led to an interruption of dosing. Thirteen of the 54 patients (26\%) who had urticaria developed it within 2 days of study treatment dosing, suggesting that the majority of the urticaria cases on secukinumab were not immediately linked to its administration. Three urticarial cases, two with secukinumab and the one with placebo described above, had a time-to-onset of urticaria from 1 to 7 days from the most recent dose of study treatment. These three urticarial cases were also accompanied by concurrent angioedema. No action was taken with study treatment in the two secukinumab treated patients, who both continued dosing throughout the maintenance period with no recurrence of urticaria or angioedema. The limited number of angioedema events arising in those patients who experience urticaria 
and the absence of recurrence upon continued dosing with secukinumab suggest that these urticaria events are case specific and not associated with an overall serious drug allergy that might be associated with anaphylaxis. ${ }^{15}$

There is limited information regarding secukinumab and the use of biologics during pregnancy. Specifically, information is missing concerning fetal malformation and incidence of spontaneous abortions. Routine pharmacovigilance may currently be the best option for pregnant women receiving secukinumab treatment. ${ }^{15}$

\section{Conclusion}

Secukinumab is a human monoclonal antibody directed against IL-17A, which is a major component of the Th17 pathway. Phase II and III trials have already demonstrated the efficacy of two other IL-17 inhibiting biologic treatments for psoriasis: ixekizumab (anti-IL-17A monoclonal antibody) and brodalumab (anti-IL-17 receptor A monoclonal antibody). ${ }^{36-38}$ However, unlike these two drugs, secukinumab has already been approved by the US Food and Drug Administration for the treatment of adults with moderate-to-severe plaque psoriasis (January, 2015). When comparing secukinumab to ixekizumab and brodalumab, patients on secukinumab treatment for plaque psoriasis have equivalent or greater PASI 75 response rates based on several Phase II trials. ${ }^{27}$ Secukinumab's Phase II trial PASI 75 response rates are also comparable to other novel Th17 pathway inhibitors such as ustekinumab (IL-12/23 inhibitor), guselkumab, and tildrakizumab (IL-23 inhibitors). ${ }^{38-40}$ As such, secukinumab shows great promise in having a tremendous impact on the treatment of plaque psoriasis based on its ability to produce similar, if not better, clinical outcomes than other biologic antipsoriasis medications.

With regard to the treatment of PsA, Phase II and III clinical trials have shown improvements in clinical responses with secukinumab treatment via accepted parameters such as ACR20 responses.

Studies have also revealed some side effects and possible safety concerns with secukinumab administration. Specifically, patients should be monitored for infectious complications such as upper respiratory tract infections and candidiasis. Furthermore, neutropenia and exacerbations of Crohn's disease are concerns. Given secukinumab's recent US Food and Drug Administration approval for widespread use in the market, further studies and postmarketing surveillance will need to be conducted in order to help determine the longer-term safety of secukinumab and other similar medications.

\section{Disclosure}

Vandana K Madkan is a consultant and speaker for Celgene and Abbvie. The authors report no other conflicts of interest in this work.

\section{References}

1. Rachakonda TD, Schupp CW, Armstrong AW. Psoriasis prevalence among adults in the United States. J Am Acad Dermatol. 2014; 70(3):512-516.

2. Gladman DD, Antoni C, Mease P, Clegg DO, Nash P. Psoriatic arthritis: epidemiology, clinical features, course, and outcome. Ann Rheum Dis. 2005;64(Suppl 2):ii14-ii17.

3. Arican O, Aral M, Sasmaz S, Ciragil P. Serum levels of TNF-alpha, IFN-gamma, IL-6, IL-8, IL-12, IL-17, and IL-18 in patients with active psoriasis and correlation with disease severity. Mediators Inflamm. 2005;2005(5):273-279.

4. Harper EG, Guo C, Rizzo H, et al. Th17 cytokines stimulate CCL20 expression in keratinocytes in vitro and in vivo: implications for psoriasis pathogenesis. J Invest Dermatol. 2009;129(9):2175-2183.

5. Ouellette AJ. Paneth cells and innate mucosal immunity. Curr Opin Gastroenterol. 2010;26(6):547-553.

6. Wilson NJ, Boniface K, Chan JR, et al. Development, cytokine profile and function of human interleukin 17-producing helper $\mathrm{T}$ cells. Nat Immunol. 2007;8(9):950-957.

7. Kolls JK, Lindén A. Interleukin-17 family members and inflammation. Immunity. 2004;21(4):467-476.

8. Hueber W, Patel DD, Dryja T, et al. Effects of AIN457, a fully human antibody to interleukin-17A, on psoriasis, rheumatoid arthritis, and uveitis. Sci Transl Med. 2010;2(52):52-72.

9. Baraliakos X, Borah B, Braun J. Long-term effects of secukinumab on MRI findings in relation to clinical efficacy in subjects with active ankylosing spondylitis: an observational study. Ann Rheum Dis. Epub August 6, 2015.

10. Letko E, Yeh S, Foster CS, et al. Efficacy and safety of intravenous secukinumab in noninfectious uveitis requiring steroid-sparing immunosuppressive therapy. Ophthalmology. 2015;122(5):939-948.

11. Baeten D, Baraliakos X, Braun J, et al. Anti-interleukin-17A monoclonal antibody secukinumab in treatment of ankylosing spondylitis: a randomised, double-blind, placebo-controlled trial. Lancet. 2013; 382(9906): 1705-1713.

12. Genovese MC, Durez P, Richards HB, et al. Efficacy and safety of secukinumab in patients with rheumatoid arthritis: a phase II, dosefinding, double-blind, randomised, placebo controlled study. Ann Rheum Dis. 2013;72(6):863-869.

13. Braun J, Kiltz U, Heldmann F, Baraliakos X. Emerging drugs for the treatment of axial and peripheral spondyloarthritis. Expert Opin Emerg Drugs. 2015;20(1):1-14.

14. Hueber W, Sands BE, Lewitzky S, et al. Secukinumab, a human antiIL-17A monoclonal antibody, for moderate to severe Crohn's disease: unexpected results of a randomised, double-blind placebo-controlled trial. Gut. 2012;61(12):1693-1700.

15. Highlights of Prescribing Information [Revised January 1, 2015]. Available from: http://www.pharma.us.novartis.com/product/pi/pdf/ cosentyx.pdf. Accessed February 23, 2015.

16. Blauvelt A, Prinz JC, Gottlieb AB, et al. Secukinumab administration by pre-filled syringe: efficacy, safety and usability results from a randomized controlled trial in psoriasis (FEATURE). Br J Dermatol. 2015;172(2):484-493.

17. Paul C, Lacour JP, Tedremets L, et al. Efficacy, safety and usability of secukinumab administration by autoinjector/pen in psoriasis: a randomized, controlled trial (JUNCTURE). J Eur Acad Dermatol Venereol. 2015;29(6):1082-1090.

18. Wang W, Wang EQ, Balthasar JP. Monoclonal antibody pharmacokinetics and pharmacodynamics. Clin Pharmacol Ther. 2008; 84(5):548-558. 
19. Strand V, Kosinski M, Gnanasakthy A, Mallya U, Mpofu S. Secukinumab treatment in rheumatoid arthritis is associated with incremental benefit in the clinical outcomes and HRQoL improvements that exceed minimally important thresholds. Health Qual Life Outcomes. 2014;12:31.

20. Papp KA, Langley RG, Sigurgeirsson B, et al. Efficacy and safety of secukinumab in the treatment of moderate-to-severe plaque psoriasis: a randomized, double-blind, placebo-controlled phase II dose-ranging study. Br J Dermatol. 2013;168(2):412-421.

21. Rich P, Sigurgeirsson B, Thaci D, et al. Secukinumab induction and maintenance therapy in moderate-to-severe plaque psoriasis: a randomized, double-blind, placebo-controlled, phase II regimen-finding study. Br J Dermatol. 2013;168(2):402-411.

22. Mrowietz U, Leonardi CL, Girolomoni G, et al. Secukinumab retreatment-as-needed versus fixed-interval maintenance regimen for moderate to severe plaque psoriasis: a randomized, double-blind, noninferiority trial (SCULPTURE). J Am Acad Dermatol. 2015;73(1): 27-36.e1.

23. Langley RG, Elewski BE, Lebwohl M, et al. Secukinumab in plaque psoriasis - results of two phase 3 trials. $N$ Engl J Med. 2014;371(4): 326-338.

24. Lønnberg AS, Zachariae C, Skov L. Targeting of interleukin-17 in the treatment of psoriasis. Clin Cosmet Investig Dermatol. 2014;(7): 251-259

25. Ohtsuki M, Morita A, Abe M, et al. Secukinumab efficacy and safety in Japanese patients with moderate-to-severe plaque psoriasis: subanalysis from ERASURE, a randomized, placebo-controlled, phase 3 study. J Dermatol. 2014;41(12):1039-1046.

26. Thaçi D, Blauvelt A, Reich K, et al. Secukinumab is superior to ustekinumab in clearing skin of subjects with moderate to severe plaque psoriasis: CLEAR, a randomized controlled trial. J Am Acad Dermatol. 2015;73(3):400-409.

27. Thaçi D, Humeniuk J, Frambach Y, et al. Secukinumab in psoriasis: randomized, controlled phase 3 trial results assessing the potential to improve treatment response in partial responders (STATURE). Br J Dermatol. 2015;173(3):777-787.

28. McInnes IB, Sieper J, Braun J, et al. Efficacy and safety of secukinumab, a fully human anti-interleukin-17A monoclonal antibody, in patients with moderate-to-severe psoriatic arthritis: a 24-week, randomised, double-blind, placebo-controlled, phase II proof-of-concept trial. Ann Rheum Dis. 2014;73(2):349-356.
29. Mease PJ, McInnes IB, Kirkham B. Secukinumab inhibition of interleukin-17a in patients with psoriatic arthritis. N Engl J Med. 2015; 373(14):1329-1339.

30. McInnes IB, Mease PJ, Kirkham B, et al. Secukinumab, a human antiinterleukin-17A monoclonal antibody, in patients with psoriatic arthritis (FUTURE 2): a randomised, double-blind, placebo-controlled, phase 3 trial. Lancet. 2015;386(9999):1137-1146.

31. Gottlieb AB, Langley RG, Philipp S, et al. Secukinumab improves physical function in subjects with plaque psoriasis and psoriatic arthritis: results from two randomized, phase 3 trials. J Drugs Dermatol. 2015;14(8):821-833.

32. Huang W, Na L, Fidel PL, Schwarzenberger P. Requirement of interleukin-17A for systemic anti-Candida albicans host defense in mice. J Infect Dis. 2004;190(3):624-631.

33. Farhangian ME, Feldman SR. Immunogenicity of biologic treatments for psoriasis: therapeutic consequences and the potential value of concomitant methotrexate. Am J Clin Dermatol. 2015;16(4):285-294.

34. Ley K, Smith E, Stark MA. IL-17A-producing neutrophil-regulatory Tn lymphocytes. Immunol Res. 2006;34(3):229-242.

35. Chioato A, Noseda E, Stevens M, Gaitatzis N, Kleinschmidt A, Picaud H. Treatment with the interleukin-17A-blocking antibody secukinumab does not interfere with the efficacy of influenza and meningococcal vaccinations in healthy subjects: results of an open-label, parallel-group, randomized single-center study. Clin Vaccine Immunol. 2012;19(10):1597-1602.

36. Leonardi C, Matheson R, Zachariae C, et al. Anti-interleukin-17 monoclonal antibody ixekizumab in chronic plaque psoriasis. $N$ Engl J Med. 2012;366(13):1190-1199.

37. Papp KA, Leonardi C, Menter A, et al. Brodalumab, an anti-interleukin17-receptor antibody for psoriasis. $N$ Engl J Med. 2012;366(13): 1181-1189.

38. Griffiths CE, Reich K, Lebwohl M, et al. Comparison of ixekizumab with etanercept or placebo in moderate-to-severe psoriasis (UNCOVER-2 and UNCOVER-3): results from two phase 3 randomised trials. Lancet 2015;386(9993):541-551.

39. Chandrakumar SF, Yeung J. Interleukin-17 antagonists in the treatment of psoriasis. J Cutan Med Surg. 2015;19(2):109-114.

40. Mease PJ. Inhibition of interleukin-17, interleukin-23 and the TH17 cell pathway in the treatment of psoriatic arthritis and psoriasis. Curr Opin Rheumatol. 2015;27(2):127-133.
Therapeutics and Clinical Risk Management

\section{Publish your work in this journal}

Therapeutics and Clinical Risk Management is an international, peerreviewed journal of clinical therapeutics and risk management, focusing on concise rapid reporting of clinical studies in all therapeutic areas outcomes, safety, and programs for the effective, safe, and sustained use of medicines. This journal is indexed on PubMed Central, CAS,

\section{Dovepress}

EMBase, Scopus and the Elsevier Bibliographic databases. The manuscript management system is completely online and includes a very quick and fair peer-review system, which is all easy to use. Visit http://www.dovepress.com/testimonials.php to read real quotes from published authors. 